\author{
HUM BERTO RODRÍGUEZ CAM ILLON I
}

VIRGINIA POLYTECHNIC INSTITUTE AND STATE UNIVERSITY

\title{
M anuel de Amat y Junyent y la Navona de Lima: un ejemplo de diseño urbano barroco del siglo XVIII en el virreinato del Perú
}

on M AnUel De Am at y Junyent Planella Aymerich y Santa Pau es una figura excepcional en la historia de la arquitectura virreinal limeña del siglo XVIII (figura I). ${ }^{I}$ Al igual que Thomas Jefferson en los Estados Unidos, Amat nos ofrece el caso raro del gobernante-arquitecto que supo aprovechar muy bien la idea de la arquitectura como símbolo de poder e instrumento de promoción cultural. La impresionante obra constructiva emprendida por Amat durante su gobierno como virrey del Perú entre 176i y i776 vistió de gala a la Ciudad de los Reyes, Lima, dándole su fisonomía colonial definitiva que perduraría a través del siglo XIX y por lo menos en parte hasta nuestros días. Según el escritor Concolorcorvo, del siglo XVIII, Amat "decoró mucho esta ciudad en paseos públicos y otras muchas obras concernientes al Estado. No puedo referirlas todas porque sería preciso escribir un volumen de a folio y otra pluma, pero nadie puede negar que su genio y su ingenio es y ha sido superior a todos los virreyes en materia de civilización y buen gusto". ${ }^{2}$ D estaca entre sus obras de

I. V éase H . Rodríguez C amilloni, "Amat (y Junyent), M anuel (de)", The Dictionary of Art, vol. I, Londres, 1996, p. 757.

2. Citado por Vicente Rodríguez Casado y Florentino Pérez Embid, M emoria de gobierno del virrey Amat, Sevilla, I947, p. LXIX. 
I48 HUMBERTO RODRÍGUEZ CAMILLONI

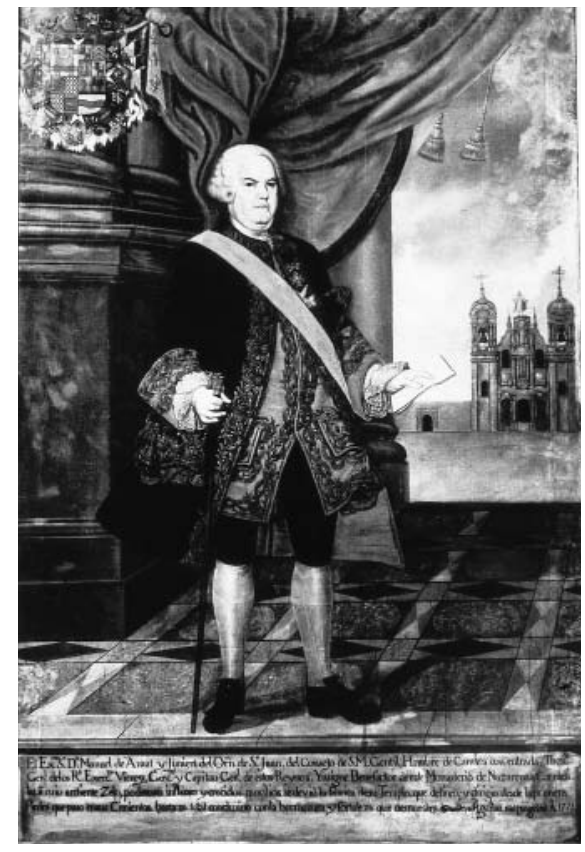

Figura i. C ristóbal Aguilar, Retrato del virrey don $M$ anuel de Amat y Junyent, I77I, Convento de Las N azarenas, Lima. Foto: A. Guillén.

valor urbanístico la antigua $\mathrm{N}$ avona de Lima, que hoy se conoce como Paseo de Aguas (figura 2), un proyecto de diseño urbano mediante el cual Amat se propuso evocar conscientemente a Roma, ciudad europea barroca por excelencia.

M anuel de Amat era natural de Vacarisas, provincia de Barcelona, España, donde había nacido en I704. Su familia noble y distinguida (fue el segundo hijo del marqués de Castellbell) le aseguró una buena educación en la tradición humanista de las artes liberales. Los datos biográficos que de él se tienen indican que desde muy temprana edad demostró su afición por las armas, adquiriendo valiosa experiencia en diversas campañas militares. M endiburu afirma que "Adoptó la carrera militar empezando á servir á la edad de once años, estuvo casi siempre en campaña y concurrió a siete batallas campales, cinco sitios, dos bloqueos y gran número de acciones y encuentros. Se hizo notar por sus proezas en la guerra de África en que permaneció cinco años; en la batalla de Bitonto (N ápoles) ganada al imperio en i736; en el asedio de Gaeta, toma de Bari \& a. Mandó con mucho crédito el regimiento Dragones de Sagunto."3 Todos estos 


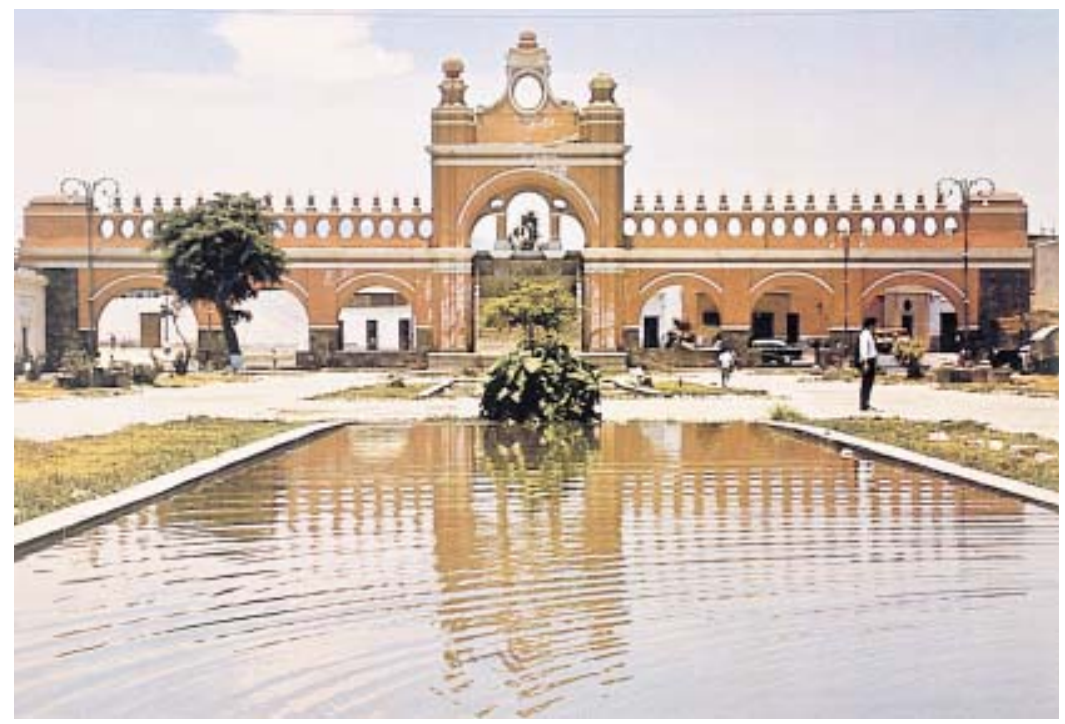

Figura 2. El Rimac, Lima, Fuente escenográfica de la Antigua N avona, hoy Paseo de Aguas, I770-1776.

antecedentes seguramente lo hicieron merecedor en 1755 de su nombramiento de gobernador y de presidente de la Audiencia de Chile y finalmente, en I76I, de su llamado para ocupar el prestigioso cargo de virrey gobernador, capitán general del Perú y presidente de la Audiencia de Lima. ${ }^{4}$

Sin embargo, para una mejor apreciación de la obra constructiva de Amat en Lima que abarcaría la gama más completa de arquitectura religiosa, civil y diseño urbano, además de ingeniería militar, es preciso esclarecer cuáles eran los conocimientos que requería en su época la carrera militar que él abrazó con tanto entusiasmo. El hombre universal del Renacimiento del siglo XvI había reconocido a la ingeniería militar o arquitectura militar como una ciencia perteneciente a las artes liberales consistente en la determinación geométrica de los elementos de fortificación. Durante los siglos XVII y XVIII, los ingenieros militares tenían que especializarse en el trazado y medida de fortificaciones, estimado de los costos y cálculo de la duración de la mano de obra. De vital importancia era el estudio de las matemáticas, aritmética y

4. Vicente Rodríguez Casado y Florentino Pérez Embid, Construcciones militares del virrey Amat, Sevilla, 1949, p. I5. 


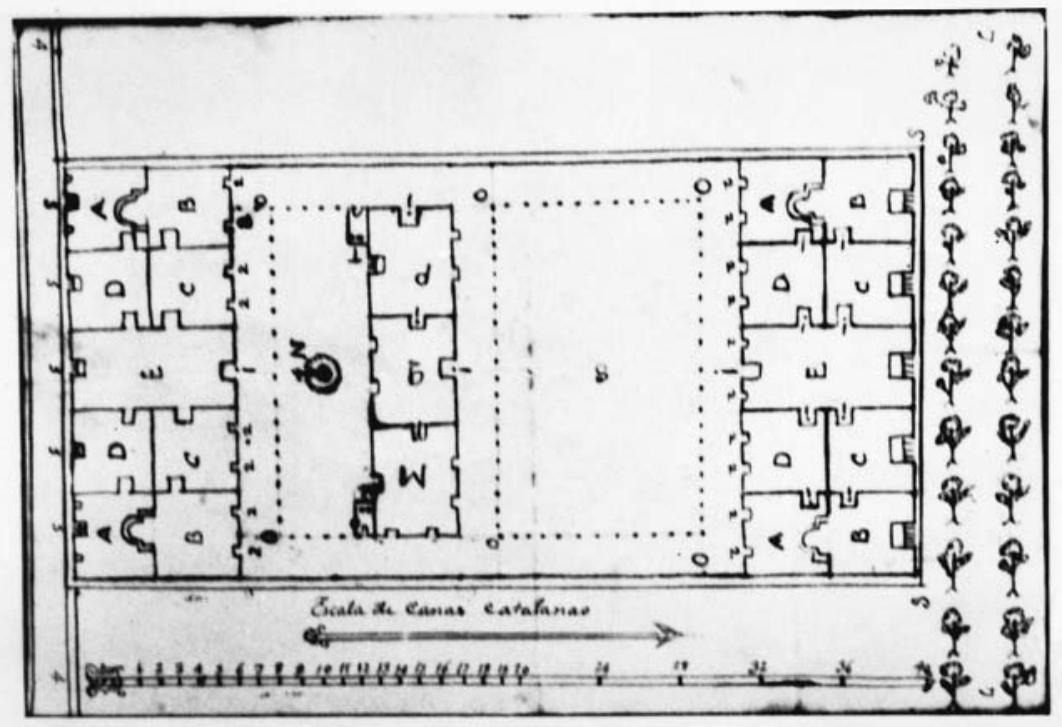

Figura 3. M anuel de Amat y Junyent, Anteproyecto del Palacio de la Virreina, Barcelona, 1767.

geometría, nivelación, conceptos básicos de mecánica e hidráulica y dibujo de mapas topográficos. E1 dibujo geométrico era estudiado para encontrar la configuración sólida de cualquier piedra o madera de un elemento arquitectónico, representar los cinco órdenes clásicos e ilustrar las plantas, cortes y elevaciones de las edificaciones civiles y militares. ${ }^{5} \mathrm{Al}$ mismo tiempo, la perspectiva se enseñaba a los ingenieros militares no sólo para determinar geométricamente el sombreado en el dibujo o la acuarela, sino también porque se estima ba esencial para lograr una verdadera percepción de la realidad.

Evidentemente Amat llegó a dominar estas técnicas representativas, ya que así lo demuestran los dibujos de su puño y letra del anteproyecto del Palacio de la Virreina en Barcelona, que envió a España en 1767 (figura 3 ). ${ }^{6} \mathrm{Y}$ no es de extrañar que varios de los planos relativos a obras proyectadas por el virrey en Lima que se conservan en la Biblioteca C entral de la Diputación de

5. Alberto Pérez-G ómez, Architectureand the Crisis of M odern Science, C ambridge, 1984, p. 199. 6. Archivo del marqués de Castell bell, en San F. de Llobregat, Barcelona. Los dio a conocer Alfredo Sáenz-Rico U rbina, El virrey Amat, 2 tomos, Barcelona, 1967. 


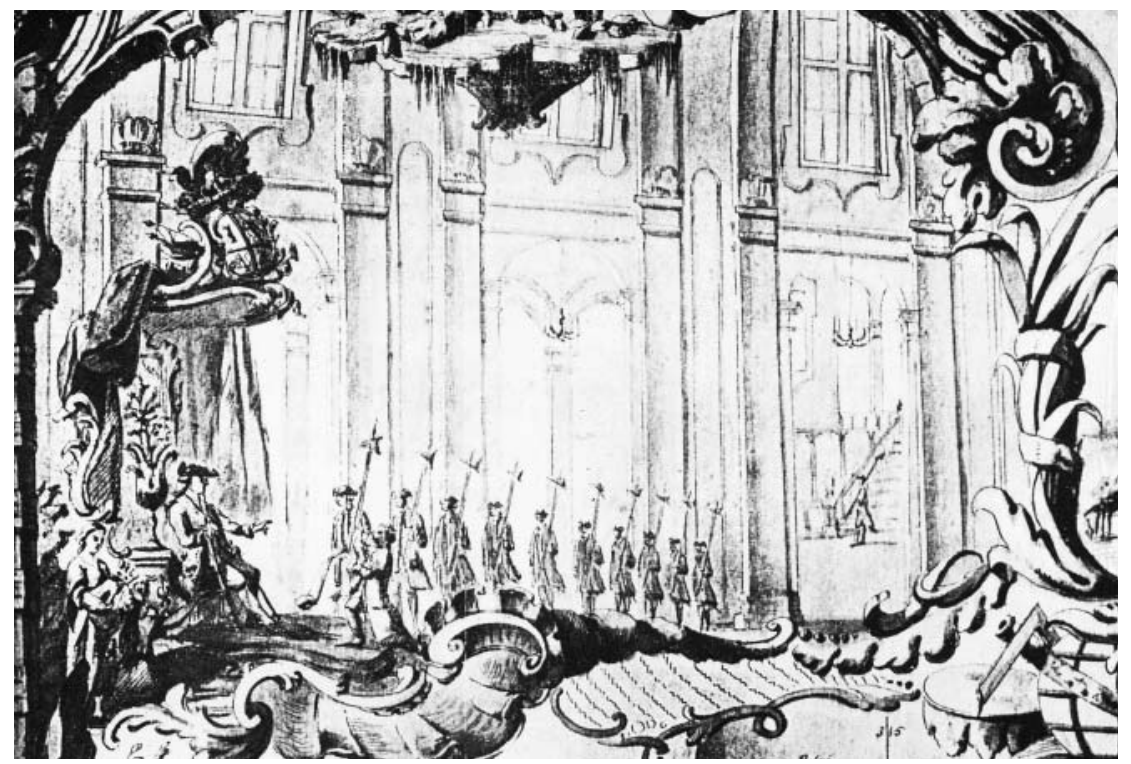

Figura 4. Lima, Escenas en el Palacio de los Virreyes, I77I. M S. 400 de la Biblioteca Central de Cataluña.

Barcelona y que fueran ejecutados en i77i bajo su dirección, son precisamente perspectivas.7 Una de éstas muestra una vista amplia de los interiores del Palacio de los Virreyes frente a los cuales se desarrolla una ceremonia militar en presencia de Amat (figura 4 ).

La arquitectura que aquí se representa debe corresponder a las transformaciones importantes que en dicho inmueble efectuó el propio virrey, incluyendo la gran escalera de piedra y galería para comunicar con la C apilla Real que se aprecia en el fondo, a mano derecha del dibujo. La abundante luz que se filtra a través de grandes ventanales sobre una danza de arcos que se repiten en diversos planos enfatiza la ligereza de las formas y la continuidad espacial de todo el conjunto.

$O$ tra perspectiva de La N avona de Lima (figura s) está dibujada desde un punto focal que coincide con el eje central de la arquería de fondo en construcción y ofrece además una vista oblicua de la portada que hacía ángulo

7. M S. 400 de la Biblioteca Central de la D iputación de Barcelona. El catálogo completo de este manuscrito lo publicó Sáenz-Rico U rbina, op. cit., II, pp. 627-658. 


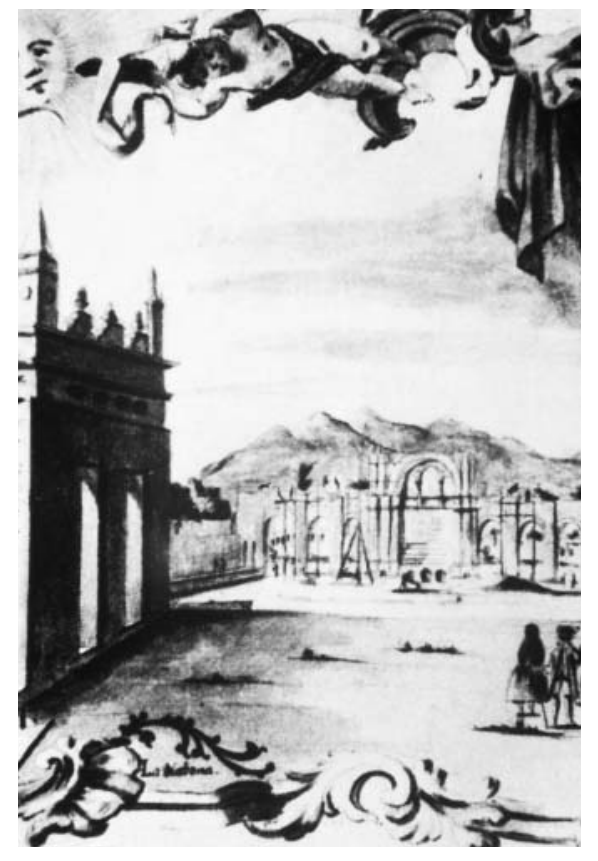

Figura 5. Lima, Vista de la N avona, I77I. M s. 400 de la Biblioteca Central de C ataluña.

con el espacio urbano contiguo de la Alameda de los D escalzos. Es importante hacer recalcar el aspecto escenográfico de estos dibujos, ya que representan una característica fundamental en la arquitectura y el diseño urbano de Amat.

Si la literatura artística moderna le ha conferido con justicia a Amat los epítetos de "virrey militarista" (Rodríguez Casado y Pérez Embid) ${ }^{8}$ y "virrey arquitecto" (H arth-Terré, Sáenz-Rico U rbina y García Bryce), 9 es necesario también reconocer que desde el punto de vista de su capacitación profesional, arquitectura e ingeniería militar fueron para él actividades paralelas y complementarias. La llegada de Amat a Lima procedente de Chile en $176 \mathrm{I}$

8. Rodríguez C asado y Pérez Embid, op. cit., I949.

9. Emilio H arth-T erré, "¿D ibujó realmente el virrey Amat lo que se le atribuye?", Cultura Peruana, vol. I, núm. I, Lima, 194I; Sáenz-Rico U rbina, op. cit.; J osé G arcía Bryce, "O bservaciones sobre cuatro obras atribuidas al virrey Amat", D ocumentos de arquitectura y urbanismo, año 3, vol. I, núm. 4, Lima, I988, pp. I2-29. 
coincidió con el momento en que la ciudad y sus alrededores apenas se recuperaban de los estragos del terremoto del 28 de octubre de i746. No obstante la obra heroica de reconstrucción emprendida por su antecesor, el virrey José Antonio M anso de Velasco, de la cual da cuenta pormenorizada, con gran tributo de elogios, Llano y Zapata en su libro E1 día de Lima (I748), 'o es evidente que aún quedaba mucho por hacer. El estado ruinoso de las fortificaciones del Callao, por ejemplo, se relata elocuentemente en el juicio de Residencia de Amat: "Estaba el Callao reducido a un simple muro exterior, en que aún era difícil montar un solo cañón, y más parecería circo para encerrar soldados que fortaleza para defender el Reino." "II

Por este motivo, al desembarcar en el puerto limeño, Amat procedió de inmediato a remediar esta situación. La guerra declarada contra Gran Bretaña en I762 hacía aún más apremiante la necesidad de defender las costas del virreinato. Como contaría el mismo virrey en su M emoria de gobierno,

El presidio del Callao lo hallé tan solamente con el simple revestimiento y delineación que formaban sus muros, faltándoles aquellos comprincipios para que fuese una competente fortaleza y seguridad, [por lo que] fue necesario emprender unos crecidos gastos para su habilitación y poner dicha plaza en estado regular de que pueda impedir cualesquiera desembarcos que intentasen hacer las naciones enemigas. ${ }^{12}$

Amat en esta oportunidad no sólo se ocupó de la restauración de las murallas del Callao, sino que hizo importantes mejoras en el Fuerte del Real Felipe, diseñado en 1746 por el ingeniero militar francés Luis G odin, y planeó la construcción de un palacio para sí mismo en el sitio, cuyos planos firmó Carlos de Beranger en I762, pero que no se llegó a realizar. ${ }^{13}$

Florentino Pérez Embid juzgó conveniente distinguir en la obra constructiva de Amat dos grandes grupos perfectamente distintos y especialmente significativos: por una parte las construcciones militares, sobre todo las forti-

Io. José Eusebio de Llano y Zapata, El día de Lima, Lima, 1748.

II. Archivo H istórico N acional, M adrid, Consejo de Indias, leg. 20.333, cuaderno 4.0, fol. 263.

I2. M emoria de gobierno, 3a. parte, cap. XxxVIII, citado por Rodríguez Casado y Pérez Embid, C onstrucciones militares del virrey Amat, op. cit., pp. III-ıI2.

13. Véase lámina vIII en Rodríguez Casado y Pérez Embid, Construcciones militares del virrey Amat, p. I84. 


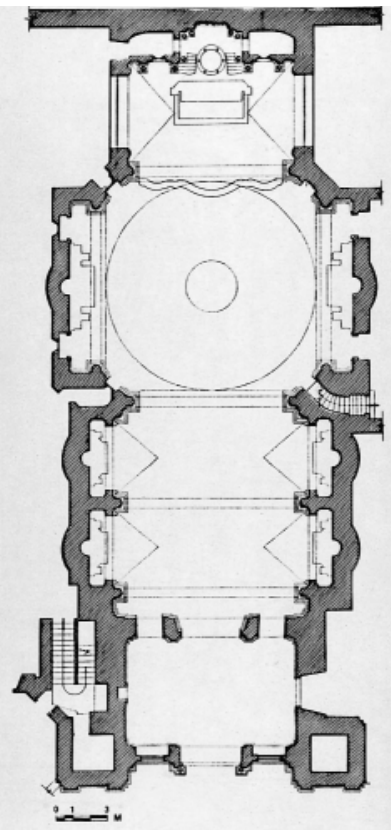

Figura 6. Lima, Planta de la iglesia de Las N azarenas, I766-I77I.

ficaciones; y por otra parte las edificaciones de carácter suntuario, entre las que se incluyen ejemplos de arquitectura civil y religiosa. ${ }^{14}$ Sobre las obras de carácter suntuario, este mismo historiador se limitó a observar que sus características formales "indican que en las ideas y en las costumbres del elemento dirigente hispanoamericano se había ya abierto camino con paso firme el espíritu francés". Is Y asimismo, que "el "barroquismo clasicista" de muchos planos y proyectos de fachada, las ligeras decoraciones rococó, la manera especial de concretar las preocupaciones urbanísticas, ponen de manifiesto el afrancesamiento aludido". ${ }^{16}$ Entre las obras arquitectónicas limeñas tradicionalmente atribuidas a Amat se encuentran la I glesia de Las N azarenas (figuras 6 y 7), la Plaza de Toros de Acho (figura 28), la Q uinta del M olino 0 Casa de la Perricholi (figura I7), el Camarín de la Virgen en la I glesia de La M erced (figuras in y I2), la Ermita de la Asunción en la huerta del Convento

I4. M emoria de gobierno del virrey Amat, op.cit., p. LXIV.

I5. Ibid., p. LXV.

I6. Ibid., p. LXV. 


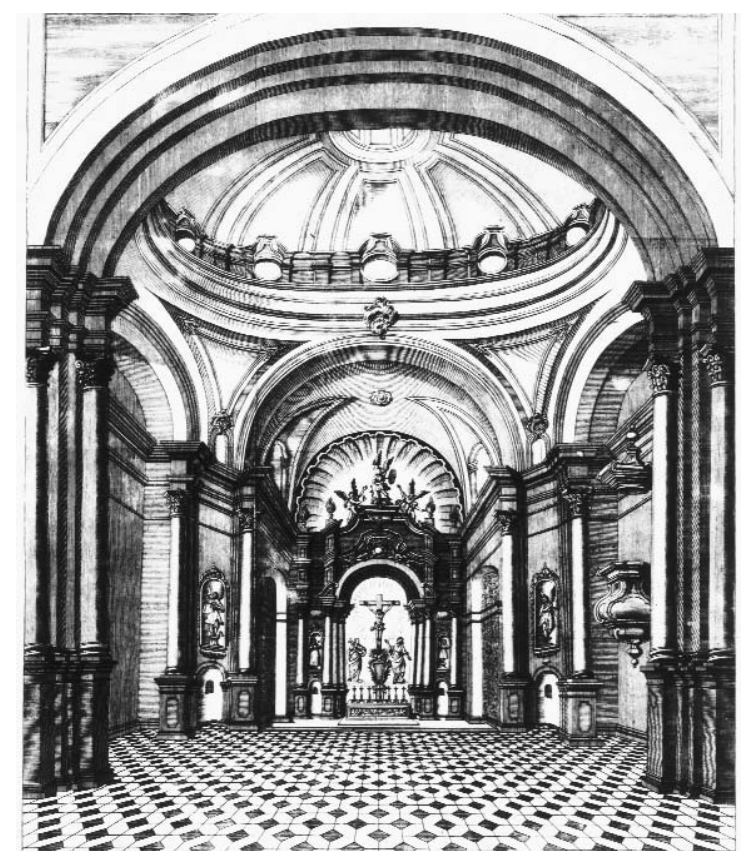

Figura 7. J osé V ásquez, Interior de la iglesia de Las N azarenas, Lima, grabado en cobre de i77I.

de N uestra Señora del Carmen, la nueva torre de Santo D omingo y la Q uinta de Presa. No es éste el lugar para hacer un análisis detallado de todas las edificaciones civiles y religiosas asociadas con Amat como su arquitecto, promotor o mecenas; pero una nueva lectura de una selección de estas obras revela que los intereses arquitectónicos del virrey fueron mucho más vastos, buscando muchas veces novedosas soluciones espaciales que se aproximan más al barroco italiano tardío de los siglos XVII y XVIII, como se evidencia en la arquitectura de Filippo Juvarra, Giovanni Battista Sacchetti y Ferdinando G alli di Bibiena.

La iglesia del Santo Cristo de los M ilagros de 1766-I77I, construida para las $\mathrm{C}$ armelitas $\mathrm{N}$ azarenas, una de las obras maestras de Amat, por ejemplo, es de nave única y muros ondulantes, rarísimos en la arquitectura virreinal peruana (figuras 6 y 7 ). Se logra aquí una extraordinaria unidad espacial de fuerte tendencia centralizante, que domina la amplia cúpula que se antepone al presbiterio. El movimiento de las columnas que se proyectan de los muros tiene eco en el juego escalonado de sus bases y molduras de los arquitrabes, 
frisos y cornisas superiores, de tal manera que, al igual que en la fachada, todas las partes se encuentran subordinadas al efecto total. Como observara bien García Bryce, "la unidad del interior se apoya no solamente en estas específicas características de forma y dimensión del espacio y en la jerarquía, orden y sentido que de ellas se derivan; ellas se sustentan además en la adopción de un sistema de elevaciones basado en la armonía y la relación coherente de los el ementos arquitectónicos entre sí". ${ }^{17}$ Participan también, en esta armonía formal, el púlpito y el altar mayor en una verdadera aproximación de la integración de las artes plásticas que Bernini en Italia calificó como un mirabile composto.

La iglesia de Las N azarenas indudablemente refleja una arquitectura basada en principios de armonía, claridad y proporcionalidad, y puede apreciarse que éstas son las cualidades que mejor se lucen en la única ilustración que acompaña el libro E1 día deseado (Lima, I77I, que publicara el mismo director general de la fábrica, don Felipe Colmenares Fernández de Córdoba, para conmemorar su inauguración: la perspectiva escenográfica del interior, grabada por José Vásquez posiblemente sobre un dibujo de Amat (figura 7 ). La paternidad de esta iglesia es por supuesto indiscutible a la luz de la evidencia documental de la época. El mismo Colmenares Fernández de Córdoba, quien dedicó su libro al virrey, lo Ilama "Inventor y dueño de la obra"; y la leyenda del famoso retrato de Amat que pintara C ristóbal Aguilar en I77I (figura I), reza textualmente: "Ynsigne Benefactor de este $\mathrm{M}$ onasterio de $\mathrm{N}$ azarenas $\mathrm{C}$ armelitas, a cuio ardiente $Z$ elo, poderoso influxo y crecidos auxilios se devió la fabrica de su Templo que delineó, y dirigió desde la primera Piedra que puso en sus Cimientos." Tomó parte también en la construcción de la iglesia el capitán de granaderos Juan de la Roca, ejecutor de varios de los proyectos de Amat. ${ }^{18}$

0 tras dos construcciones religiosas que estilísticamente se relacionan con Las $\mathrm{N}$ azarenas y que bien podrían vincularse con el virrey Amat, aunque no se ha encontrado documentación que así lo demuestre, son la Capilla de San $M$ artín de Porres dentro del conjunto monástico de Santo D omingo (figuras 8 y 9) y la Capilla O ratorio, aledaña al claustro principal del Convento de Las M ercedarias (figura ıo). Interesa señalar sobre todo el carácter escenográfico de los espacios interiores, donde se busca una unidad de conjunto. El

17. G arcía Bryce, op.cit., p. i8.

I8. H arth-Terré, op.cit., y Rubén V argas U garte, Ensayo de un diccionario de artífices de la América meridional, 2a. ed., Burgos, 1968, p. 453. 
Figura 8. Lima, Planta dela capilla deSan M artín de Porres, Santo D omingo.

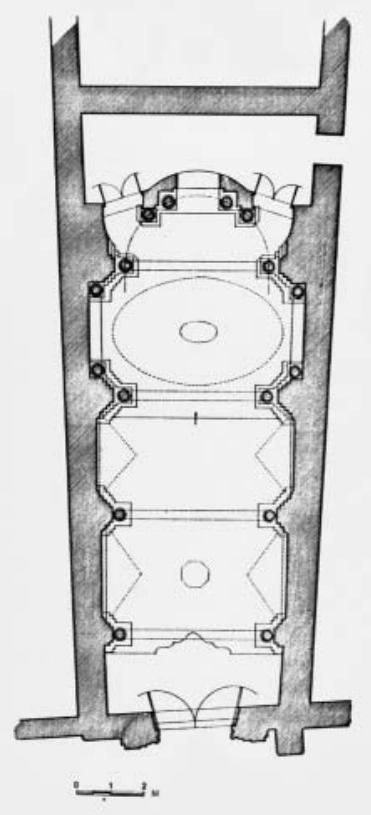

investigador San Cristóbal ha considerado la capilla dominica "una de las más notables expresiones de la arquitectura limeña posterior al terremoto de 1746", añadiendo que "aunque no he encontrado ningún documento referente a su construcción, considero que esta capilla en su traza actual debió haber sido edificada por los mismos años que la iglesia de Las $\mathrm{N}$ azarenas, el camarín de la Virgen en la iglesia de La M erced, y también acaso la segunda torre de la iglesia de Santo D omingo". 19 Sólo un levantamiento topográfico revela la originalidad de su planta trapezoidal de una sola nave, cuyo tercer tramo culmina en una cúpula elíptica que domina el espacio frente al altar (figura 8). La separación de las columnas de los muros es aquí total, creando el efecto airoso que es característico del estilo rococó del siglo XVIII, y el movimiento escalonado de las pilastras crece en intensidad desde la entrada hasta el altar que se integra con el movimiento de cada una de las partes a la rítmica articulación de los demás elementos arquitectónicos. La iluminación

19. Antonio San C ristóbal, Arquitectura virrénal religi osa de Lima, Lima, 1988, p. I38. 


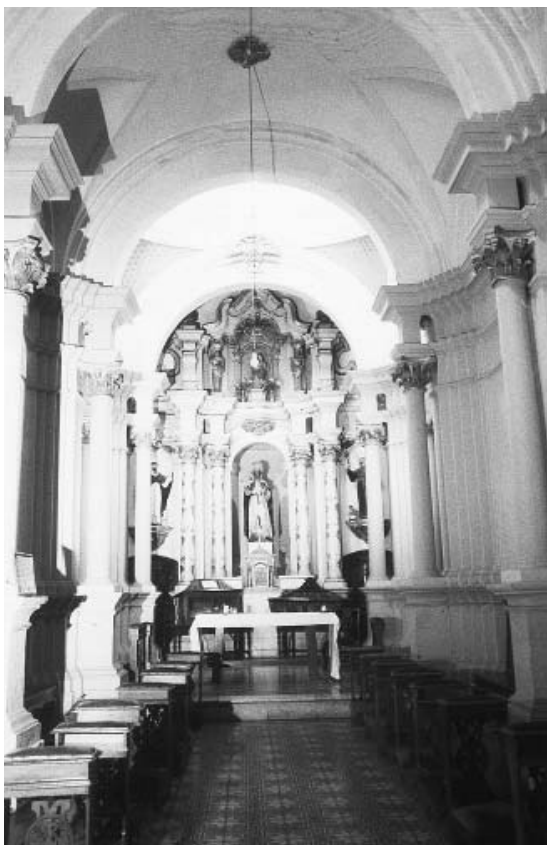

Figura 9. Lima, Interior dela capilla de San M artín de Porres, Santo D omingo.

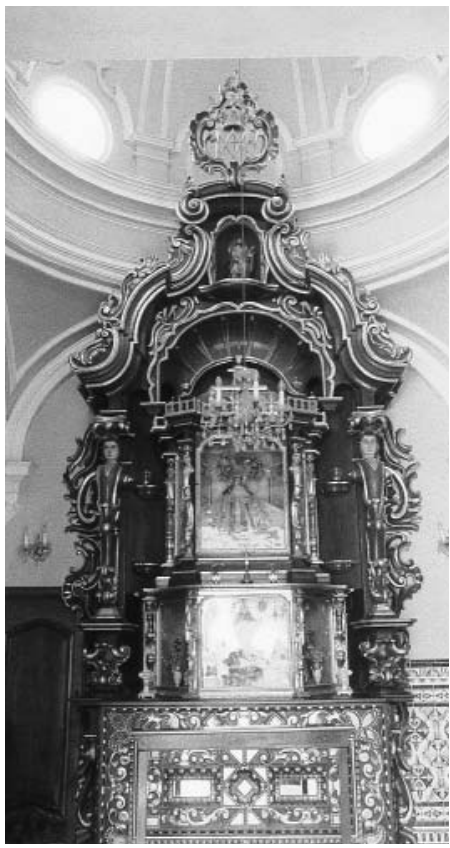

Figura io. Lima, Interior dela capilla O ratorio de Las M ercedarias, C. 1775 .

de la cúpula y del camarín detrás del altar intensifican el aspecto escenográfico de todo el espacio (figura 9).

La Capilla O ratorio de Las M ercedarias, C. I775, en cambio, es un diseño más simple de planta cuadrangular sobre la que se levanta una cúpula semiesférica de modestas proporciones (figura io). Con sorprendente economía de elementos, aquí se logra un fondo escenográfico eficaz en el que las formas curvilíneas del altar armonizan con las molduras de las pechinas, al mismo tiempo que inician un movimiento ascendente que culmina en la linterna de la cúpula. Es un espacio perfectamente centralizado cuya unidad recuerda los principios de armonía, claridad y proporcionalidad observados anteriormente en la iglesia de Las $\mathrm{N}$ azarenas.

Sin embargo, para García Bryce, la obra de Amat que alcanzó la mejor unidad de armonía o correspondencia entre las partes fue el Camarín de la Virgen de I77I-I774 en la iglesia de La M erced (figuras ir y I2). ${ }^{20}$ La planta 


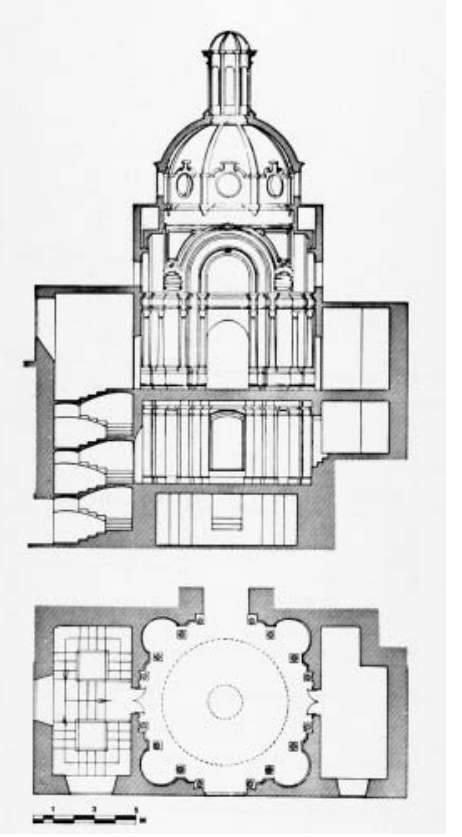

Figura ir. Lima, Planta y corte del Camarín de la Virgen, La M erced, I770-I773.

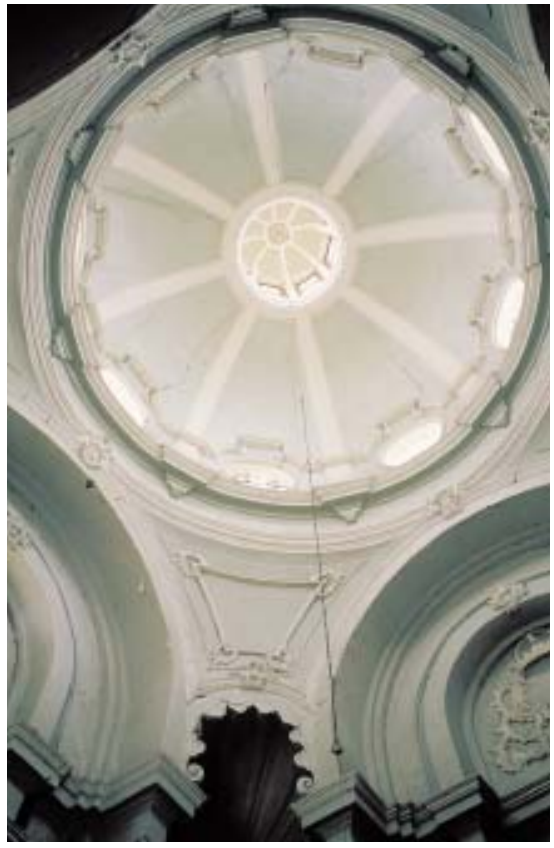

Figura ı2. Lima, Interior de la cúpula del Camarín dela Virgen, La M erced.

central del camarín se inscribe en un cuadrado perfecto de esquinas redondeadas, pero su acceso se realiza a través de una escalera de novedoso diseño espacial:

Luego del primer tramo central, la escalera se bifurca y luego vuelve a unirse, formando una planta en doble cuadrado. Los tramos y descansos son una leve estructura de madera recubierta con caña y yeso que forma arcos rampantes que se apoyan en los muros de la caja de la escalera y, en la parte interna, en columnillas de madera unidas a las balaustradas de barrotes torneados... El trayecto desde los espacios de la parte baja de la escalera, en penumbra y poblado por las columnillas que se repiten en cada descanso, hasta el último tramo, mucho más iluminado, alto y despejado, y de allí al camarín mismo, con su elevada cúpula y sugestiva forma espacial, es singularmente atrayente. ${ }^{2 \mathrm{I}}$ 
160 HUMBERTO RODRÍGUEZ CAMILLONI

De esta manera, el espacio luminoso del camarín, dominado por la cúpula que se levanta sobre pechinas trapezoidales apoyadas sobre esbeltas columnas corintias separadas de los muros, se convierte en la culminación de un modulado recorrido espacial, Ileno de anticipación. La forma espacial del camarín está basada en la geometría del octógono, de donde surge el sistema de dobles apoyos de los arcos que sostienen la cúpula, de diámetro mayor que el de los arcos. Esta forma nos hizo pensar también en la iglesia de Sant'Agnese (1652) de Borromini, en Roma, como una posible fuente de inspiración. Y se preguntó García Bryce: "¿Estaban los supuestos autores del camarín, Amat y de la Roca, familiarizados con los libros de grabados que ilustraban las iglesias romanas y específicamente la de Santa I nés?" 22 Es difícil dudarlo, a nuestro parecer, ya que la Piazza N avona (figura i4) donde se ubica esa iglesia serviría de inspiración a su principal proyecto de diseño urbano en la capital del virreinato del Perú.

D esde un principio se interesó el virrey Amat por el ornato de las calles y los espacios abiertos de la ciudad, tema del cual se ocupa en el capítulo tercero de la M emoria de su gobierno, titulado "Composiciones de caminos, aseo y limpieza de las calles y diversiones públicas". Atrajeron su atención los caminos que comunicaban la ciudad con el puerto del Callao y los valles que la rodean. Como él mismo explica:

cuando entré á esta C iudad, todos estimaban por lo descompuestos que se hallaban los caminos Reales y abenidas respectivas, formándose unos Pantanos y lodazales que hacian no solamente dificil, sino absolutamente intransitables el tragin, y comercio de los $\mathrm{H}$ acendados, vecinos, y de otros que conducen continuamente cargas á esta C apital, lo qual dimanaba de los derrames de Aguas de las inmediatas $\mathrm{H}$ aziendas de estos $\mathrm{V}$ alles, ocasionándose por esta causa algunas desgracias, perdidas y atrazos que se experimentaban, lo que procuré remediar con el mayor Exfuerzo [sic] y empeño, de suerte que se lebantaron Puentes y se limpiaron las veredas del Callao y de los Valles de Carabeillo y Late y demás entradas. ${ }^{23}$

Entre estos caminos, el de Lurigancho se hallaba interceptado en parte por el saliente que hacía el cerro de San Cristóbal en el lugar denominado de Piedra Lisa, ubicado "debajo del puente", actualmente distrito de El Rimac.

22. Ibid., p. 25 .

23. Rodríguez Casado y Pérez Embid, M emoria de gobierno del virrey Amat, p. i67. 
Figura i3. El Rimac, Lima, Vista aérea del sector de la Alameda de los $D$ escalzos y la Antigua $N$ avona, hoy Paseo de Aguas. Servicio Aerofotográfico N acional.

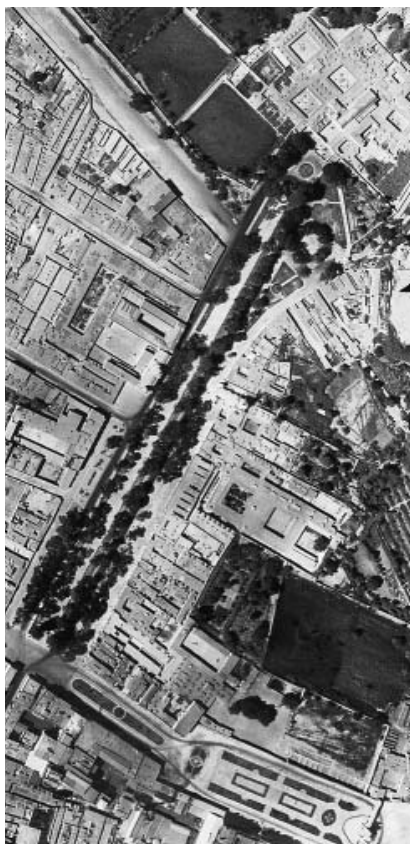

Amat hizo volar aquella estribación rocosa y dio paso a los vehículos y las gentes que poblaban ese fértil valle mediante una hermosa alameda de árboles que se conoció como la Alameda N ueva y que se conservó hasta los primeros años del siglo xx (figura 29). Amat calificó esta obra como "uno de los paseos de diversión en coches que tiene el vecindario con una dilatada y frondosa Alameda [N ueva] que tengo hecha y fomentada á mis espensas". ${ }^{24}$ En realidad, el camino de la Piedra Lisa hacia el valle de Lurigancho abrió un cauce amplio a la expansión urbana más allá del damero de Pizarro, con un aprovechamiento inteligente de las bellezas naturales, y, lo que es más importante desde el punto de vista de un nuevo diseño urbano, vino a formar un todo ininterrumpido con la vieja Alameda de los D escalzos de i6II y La $\mathrm{N}$ avona, que fue su máxima creación como espacio abierto (figura i3).

El punto de partida de este ambicioso esquema urbano debió ser el atractivo que le brindó a Amat la Alameda de los D escalzos (figura is), cuyas proporciones y características formales le harían recordar la Piazza N avona de Roma. 


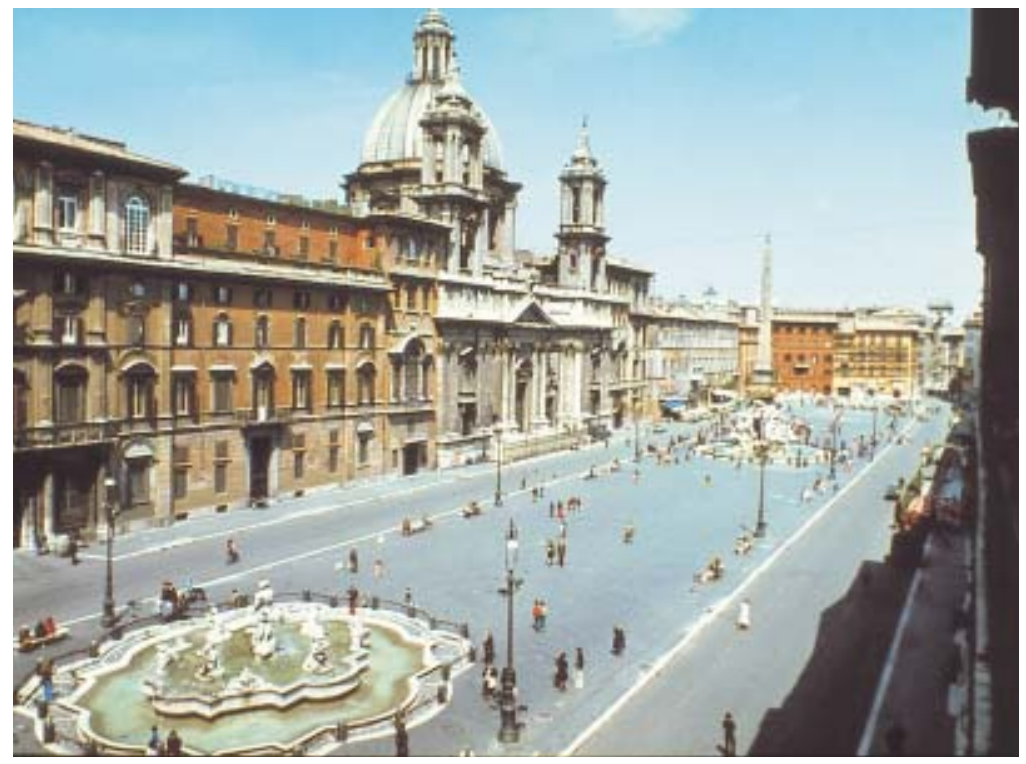

Figura i4. Roma, Vista panorámica de la Piazza N avona, siglo xVII.

A poco tiempo de mi Govierno reconocí el paseo publico de la Alameda [de los D escalzos] - escribe Amat- cuyas fuentes se hallaban desbaratadas, y los Arboles sin aquel verdor que ofrece diversión y complacencia. Estos lugares en todas las Ciudades politicas se mantienen para desaogo de los ánimos en aquellos tiempos que se conceden al descanso y así, al instante procuré remediar el desorden que se notaba, poniendo corrientes sus Pilas, replantando Árboles, y formando asientos y calles para la gente bulgar, á fin de que no se atropellasen con los muchos $C$ oches y Calesas que concurren los dias festibos, principalmente en los primeros del año, con ocasion de pasar el Virrey con los Alcaldes ordinarios segun costumbre establecida. M e pareció estender el paseo á mayor distancia, pues se han hecho juegos de Aguas, cuya maquina á imitacion de la que ay en Roma, llegando á su perfección será uno de los mas hermosos recreos que pueda tener Ciudad alguna, deviendo expresar [...] que mis deseos han sido decorar á esta Republica por quantos medios han sido posibles dandole aquel esplendor que se merece. ${ }^{25}$ 
DOI: http://dx.doi.org/10.22201/iie.18703062e.1999.74-75.1874

MANUEL DE AMAT Y JUNYENT Y LA NAVONA DE LIMA

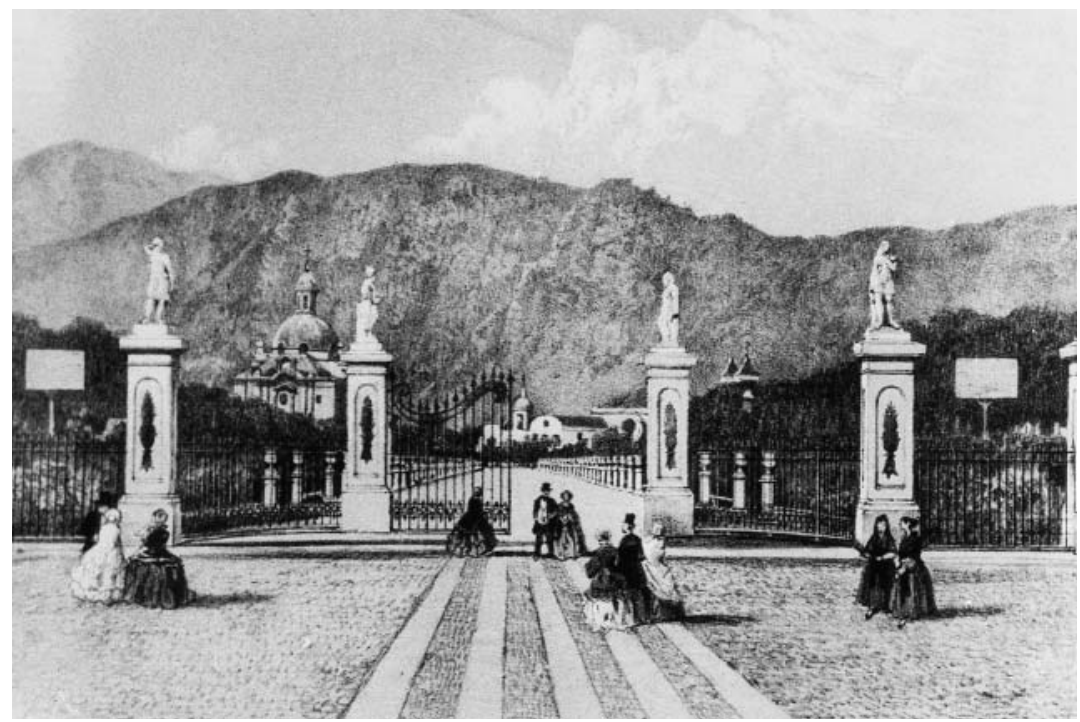

Figura Is. El Rimac, Lima, La Alameda de los D escalzos en una litografía del siglo XIX. Colección M. González Salazar.

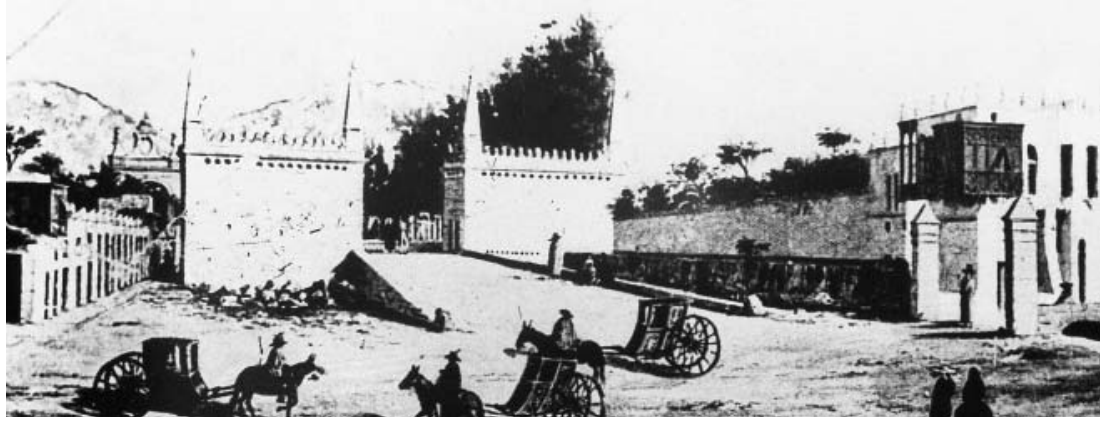

Figura i6. El Rimac, Lima, Vista del Paseo de Aguas en el siglo xıx. Colección M. González Salazar. 


\section{I64 HUMBERTO RODRÍGUEZ CAMILLONI}

La referencia específica aquí a Roma es importante también porque indica la persistente idea de la Ciudad Eterna como cabeza principal del mundo civilizado cristiano. Lejos de ser una copia de la Piazza Navona, la Alameda de los $D$ escalzos, sin embargo, dotó a la ciudad de un espacio urbano dinámico concebido como gran escenario de actividades humanas. $Y$, al igual que la plaza romana, reflejando el espíritu de la época, la alameda sirvió de telón de fondo a múltiples festividades civiles y religiosas, como los paseos en coches y calesas tan de gusto del virrey. Como se puede recordar, en la Piazza Navona, construida sobre lo que fuera un antiguo circo romano, todas las edificaciones civiles se subordinan a la iglesia de Sant'Agnese, cuya fachada imponente de torres gemelas domina el espacio desde uno de los frentes largos (figura I4). La famosa fuente de Los Cuatro Ríos (1648-165I), de Bernini, complementada por otras dos fuentes de menor tamaño, anima el espacio central y se une en juego armonioso al movimiento dinámico de las formas arquitectónicas. En los D escalzos (figura I8), en cambio, no una sino tres iglesias contribuyen, con sus fachadas, a definir el espacio abierto de diferente manera cada una: en el extremo norte, la iglesia y el monasterio de los D escalzos (figura 25) marcan un dominante punto focal; en el lado oriental, la iglesia de N uestra Señora del Patrocinio (figura 26) presenta su fachada principal de torres gemelas; mientras que en $\mathrm{e}$ lado occidental se ubica la iglesia de Santa Liberata (figura 24), con su fachada lateral paralela al eje longitudinal de la alameda.

Amat Ilamó La N avona al espacio urbano que creó en el extremo sur de la Alameda de los $D$ escalzos, formando un ángulo ligeramente obtuso con ésta hacia el oriente, no motivado por un afán de imitación formal sino más bien con el fin de evocar explícitamente los principios de diseño urbano que caracterizan a la famosa plaza romana. Vale la pena recordar que durante el siglo XVIII las referencias históricas eran reconocidas con aprecio como un modo legítimo de perpetuar la tradición. Ampliando de esta manera el espacio existente de la Alameda de los D escalzos (figura i8), Amat logró un enriquecimiento espacial urbano que - se podría pensar - hubiera deleitado incluso a Bernini y Borromini, dos de los grandes exponentes del barroco italiano del siglo anterior.

Geométricamente, el espacio de La N avona de Lima, cuyo nombre todavía se lee en el plano de la ciudad publicado por $M$ anuel $A$. Fuentes en ${ }^{18} 88^{26}$ se desarrolla en dos franjas alargadas consecutivas, en cuya unión se 


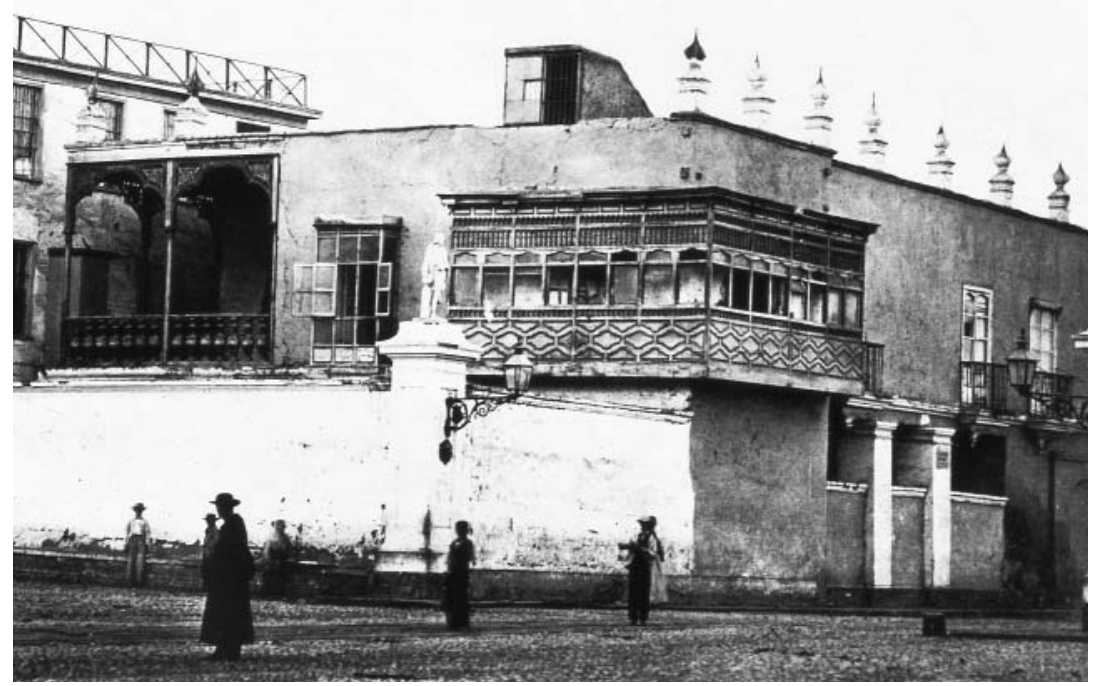

Figura i7. El Rimac, Lima, Casa de M icaela Villegas, "La Perricholi”, en una fotografía antigua. Archivo A. Guillén.

produce un ligero quiebre agudo en el eje longitudinal, que termina en una fuente escenográfica hacia el este (figuras 2 y 27 ). Esta fuente de diseño dinámico consistente en un frontis arquitectónico flanqueado por danzas de tres arcos escarzanos a cada lado, y animado remate de ventanas ovales y pináculos piramidales con vista hacia el paisaje de los cerros, sirvió de telón de fondo y foco principal de todo el espacio. Tal vez, urbanísticamente, la función de esta fuente fue muy similar a la famosa Acqua Felice de Roma que el papa Sixto $\mathrm{V}$ encargó construir a D omenico Fontana a fines del siglo XVI.

D el otro extremo, el ingreso a La $\mathrm{N}$ avona se realizaba a través de una rampa y portada de dos muros exentos con remates piramidales, que enmarcaba y anticipaba el juego volumétrico de la fuente del fondo (figura i6). Grabados y fotografías del siglo pasado nos permiten una mejor apreciación de estas relaciones formales y espaciales. En algunas de ellas aparece también la Q uinta del M olino o la casa de la famosa M icaela Villegas, "La Perricholi" (figura ${ }_{17}$ ), que la historia y probablemente más la leyenda han relacionado románticamente con el virrey Amat. Aunque no fuera exacto, como han afirmado algunos autores, que La N avona sólo fue "obra de ornato y galantería 
que mandó erigir el virrey Amat para solaz de su amante", ${ }^{27}$ la casa de la Perricholi ocupaba un lugar estratégico en la composición urbana, definiendo una de las esquinas medianeras entre la Alameda de los D escalzos y La Navona. Era sin duda alguna "un precioso palacete del más puro estilo limeño", ${ }^{28}$ cuyo balcón esquinero volado y gal ería alta posterior permitían las mejores vistas de todo el monumental conjunto urbano (figura i6).

Como toda obra pública, la construcción de La N avona significó un gasto mayor, y cuando Amat dejó Perú, en 1776, los trabajos quedaron inconclusos. Sin embargo, también en el aspecto de su financiación el virrey demostró su ingenio, según cuenta $M$ anuel de 0 driozola (I873) en la "N oticia de la plata que se recogió en la mesa que puso el virrey Amat para la obra del Paseo de Aguas":

El Domingo de Cuasimodo del año de I770, que cayó á 22 de Abril, dispuso el Virrey Amat, que en ese día se pusiese una mesa en la puerta de la iglesia de los D esamparados, para que en ella oblasen las personas que al efecto fueron convidadas por la comisión que nombró, compuesta de los señores $\mathrm{D}$. Antonio Amat, sobrino del Virrey; los 0 idores, 0 rrantia y Q uerejazu, y el Alcalde ordinario D. Pedro José de Zárate. Los expresados señores asistieron á la mesa á recibir las ofrendas, acompañados de lo principal de la nobleza, desde las seis de la mañana en que comenzó la erogación hasta las diez de la noche en que concluyó. Entonces se procedió á investigar la cantidad recojida, y resultó ser mas de veinticinco mil pesos [...] El 24 del referido mes y año, se procedió á la obra tirándose las lineas desde el pié del cerro de San Cristóbal hasta la entrada de la antigua alameda de los $D$ escalzos: y faltando dinero, se paso otra mesa en la que el día I4 de Junio de I772, se recogieron diez y seis mil y pico de pesos. H allándose el trabajo en el mejor estado, se desplomó una cortina de la frontera que tenia ya mas de ocho varas de alto: $y$ tanto por este incidente, falta de fondos, $y$ la cesacion en el mando del Virrey, quedó la obra como hoy se encuentra. ${ }^{29}$

La originalidad de la concepción urbanística de Amat consistió en reconocer el potencial de las calles de la ciudad como un sistema armonioso de desplazamiento. Su predilección por la experiencia del espacio dinámico puede ayudar a explicar por qué el mayor reordenamiento urbanístico que

27. Juan M anuel U garte Eléspuru, Lima incógnita, Lima, I992, p. 98.

28. Ibid., p. 99.

29. M anuel de $O$ driozola, D ocumentosliterarios del Perú, tomo IV, Lima, I873, pp. 323. 


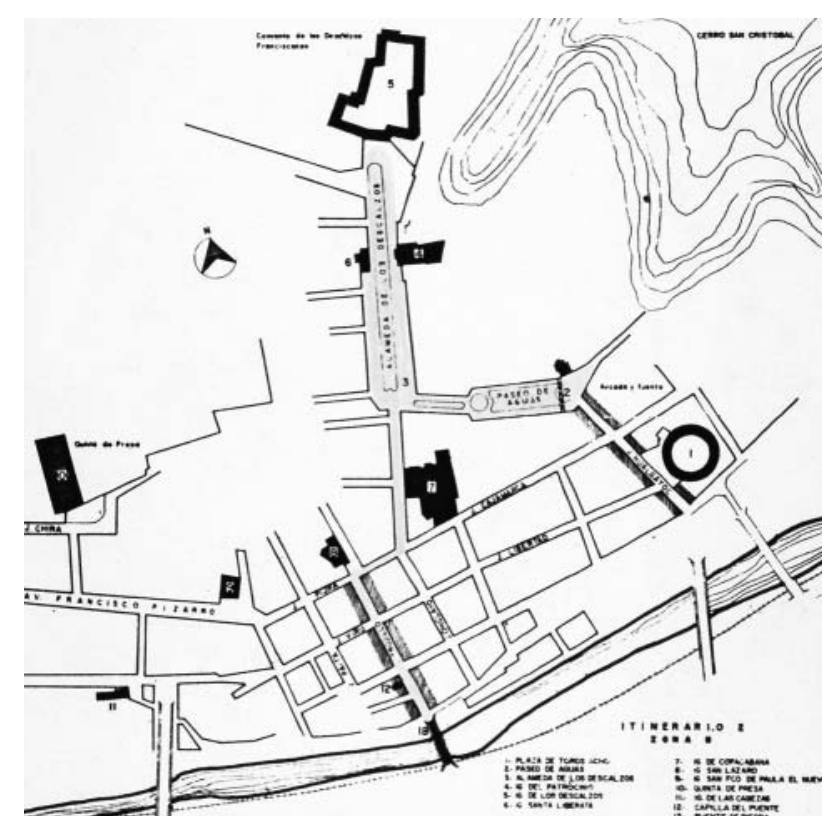

Figura i8. El Rimac, Lima, Plano monumental con el Paseo de Aguas, núm. 2, y la Alameda de los D escalzos, núm. 3. H. Velarde.

emprendió en la ciudad de Lima fue en el distrito de El Rimac. En este sector de la ciudad (figura ı3), sobre todo por razones topográficas, ya desde tiempos anteriores se había modificado el damero original de Pizarro, permitiendo una geometría más variada de red de calles y espacios abiertos como el de la Alameda de los D escalzos (figura i8). El contraste entre el espacio relativamente estático de la Plaza M ayor (figura ig) y el espacio dinámico de la al ameda (figura is) debió haber sido percibido especialmente por el virrey.

Si se sigue un recorrido ceremonial por el sector de EI Rimac como el que seguramente pudo haber hecho Amat, se puede captar el alcance de su visión urbanística. Para ello es necesario recurrir otra vez a grabados y fotografías antiguas que dan una idea más completa de las características formales de los edificios y espacios abiertos de la época. Partiendo del Palacio de los V irreyes en el extremo norte de la Plaza M ayor (figura i9), el séquito de coches y calesas hubiera tomado la calle Fierro Viejo (figura 20) a mano izquierda, que desembocaba en la plazuela de la iglesia de Los D esamparados. M arcaba el 


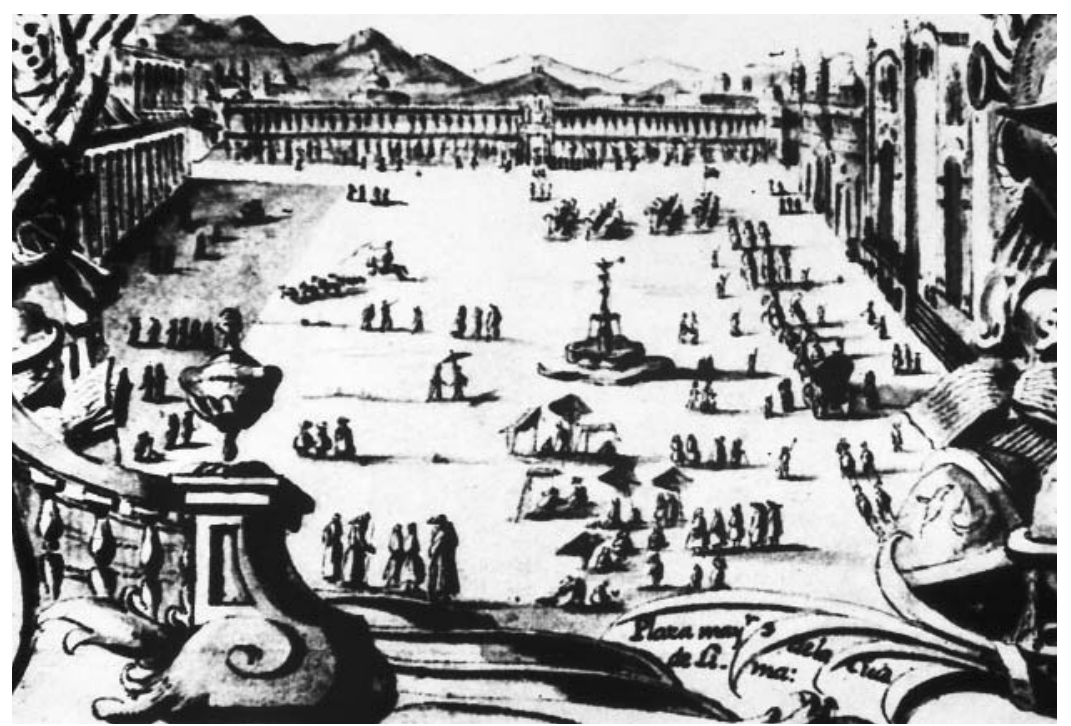

Figura i9. Lima, Plaza mayor y frente del Palacio de los Virreyes. M S. 400 de la Biblioteca Central de Cataluña.

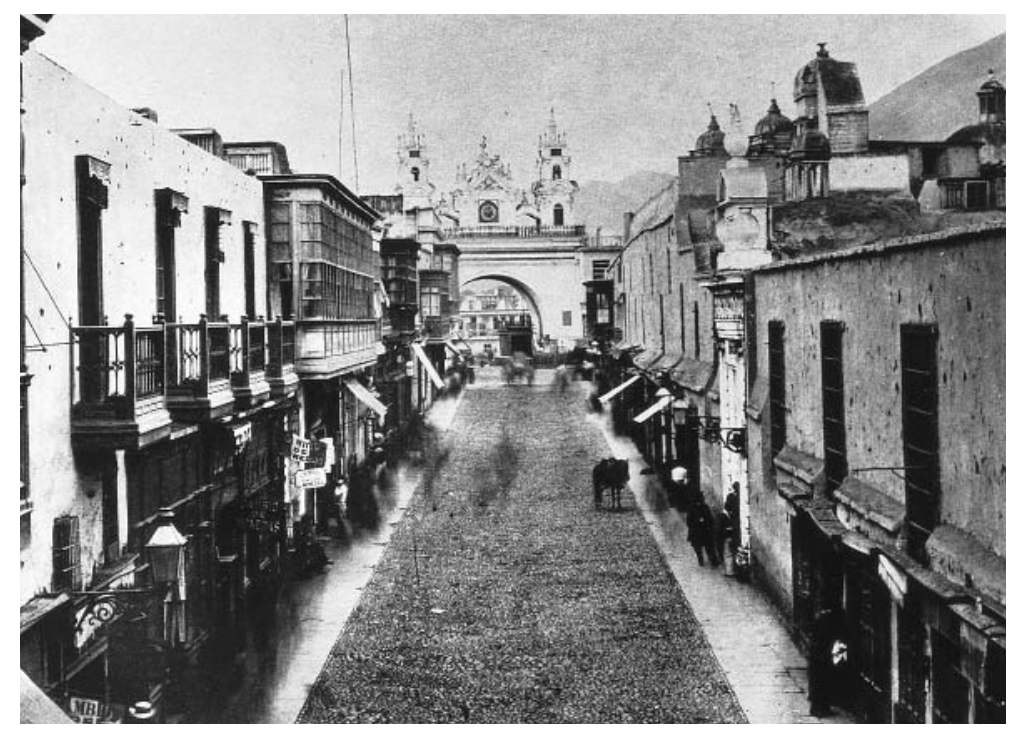

Figura 20. Lima, Calle Fierro Viejo y Arco del Puente en una fotografía de i865. Archivo A. Guillén. 


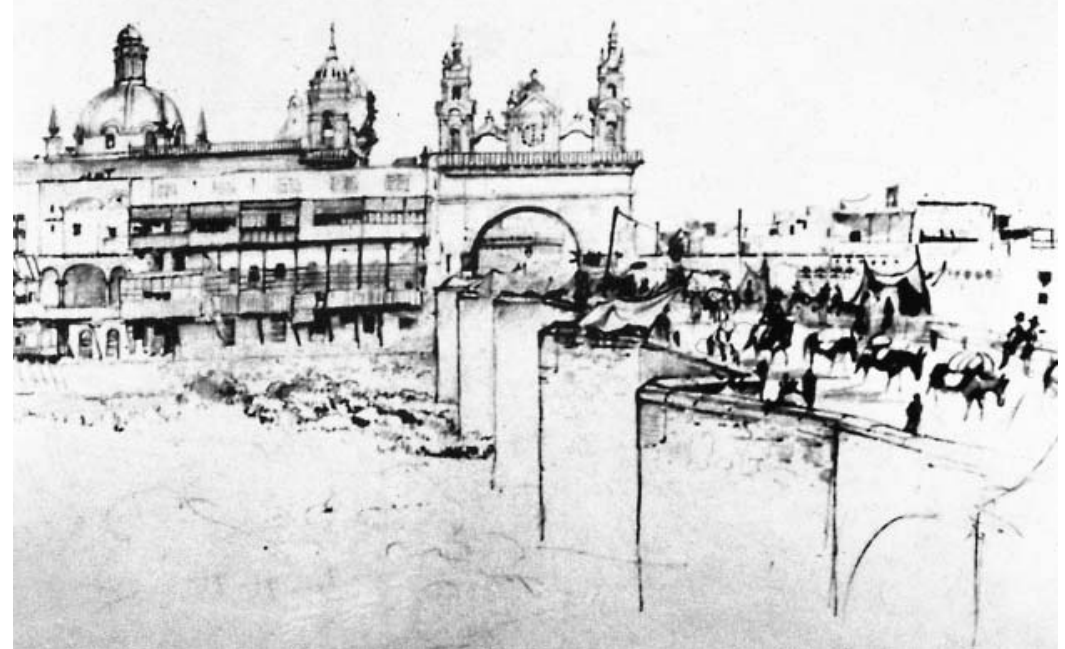

Figura 2I. Juan M auricio Rugendas, El Puente de Piedra o de M ontesclaros, dibujo al lápiz, c. I842.

término de esta calle el famoso Arco del Puente, construido en i7oo, que servía de portada triunfal de entrada a la ciudad desde el barrio de San Lázaro, y que había sido también restaurado por el virrey Amat. A su vez, este arco engalanaba el acceso al Puente de Piedra de i6o9 (figura 2I), que cruzando el río Rimac comunicaba con la recta (hoy jirón Trujillo) que terminaba en la iglesia de San Lázaro. En la intersección con la plazuela de esta iglesia, hubiera doblado a la derecha a la calle M iranda, para tomar enseguida a mano izquierda la recta de las calles Frontón y M olino (hoy jirón Chiclayo), pasando enfrente de la iglesia de N uestra Señora de Copacabana (figura 22) y desembocando en la Alameda de los D escalzos (figura 23). D esde este punto, un circuito completo alrededor de la alameda en sentido del reloj hubiera permitido en sucesión la vista de la I glesia de Santa Liberata (figura 24), la I glesia y M onasterio de los D escalzos (figura 25) y la Iglesia de N uestra Señora del Patrocinio (figura 26). Llegando al extremo sur de la alameda nuevamente, se hubiera entrado a La Navona hacia la izquierda y siguiendo su recorrido hasta el fondo, pasando por la fuente escenográfica (figuras i6 y 27), se podría todavía continuar en dirección sureste por el jirón $\mathrm{H}$ ual gayoc hasta la Plaza de Toros de Acho (figura 28), otra de las principales 
DOI: http://dx.doi.org/10.22201/iie.18703062e.1999.74-75.1874

170 HUMBERTO RODRÍGUEZ CAMILLONI

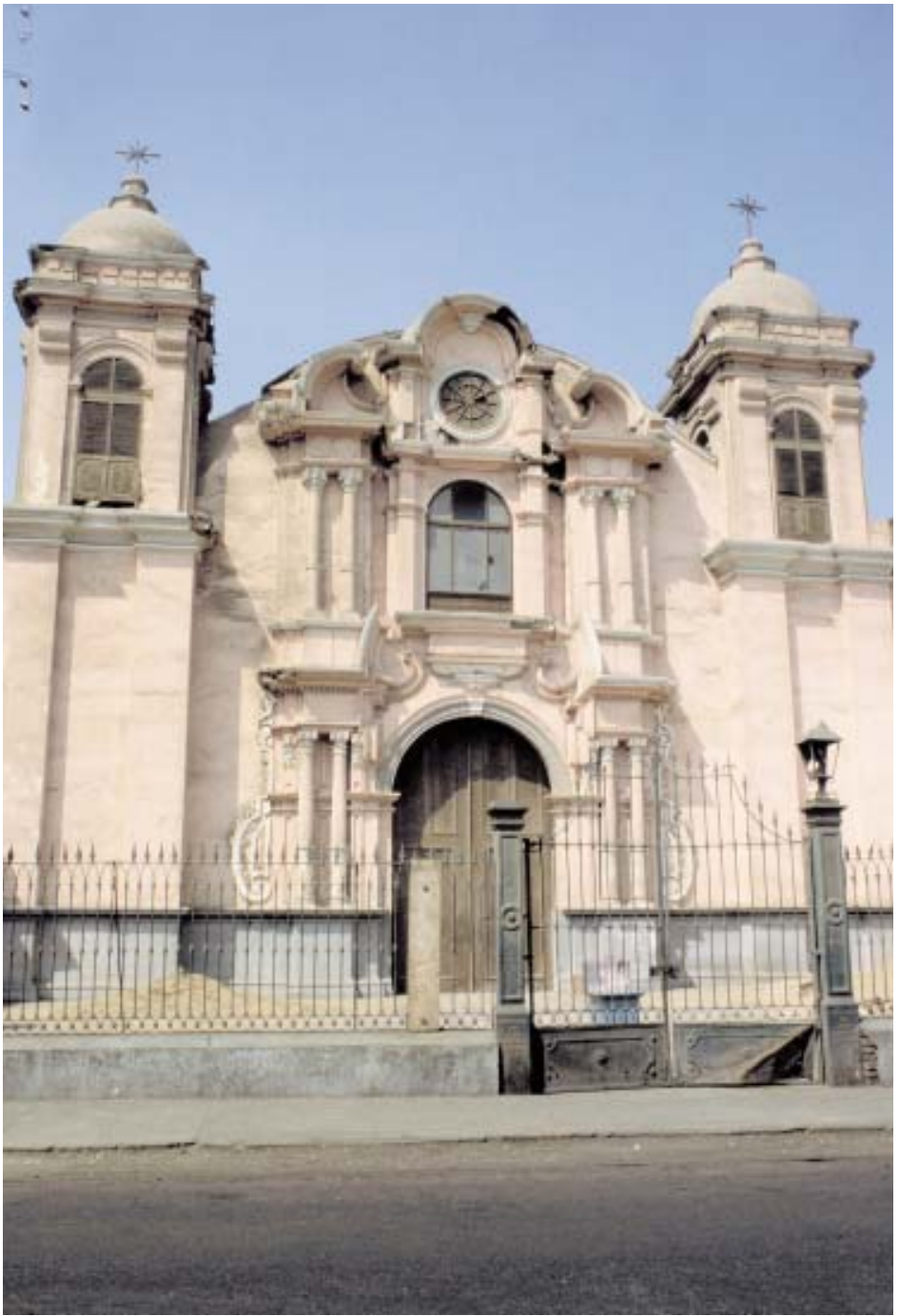

Figura 22. El Rimac, Lima, I glesia de N uestra Señora de Copacabana. 


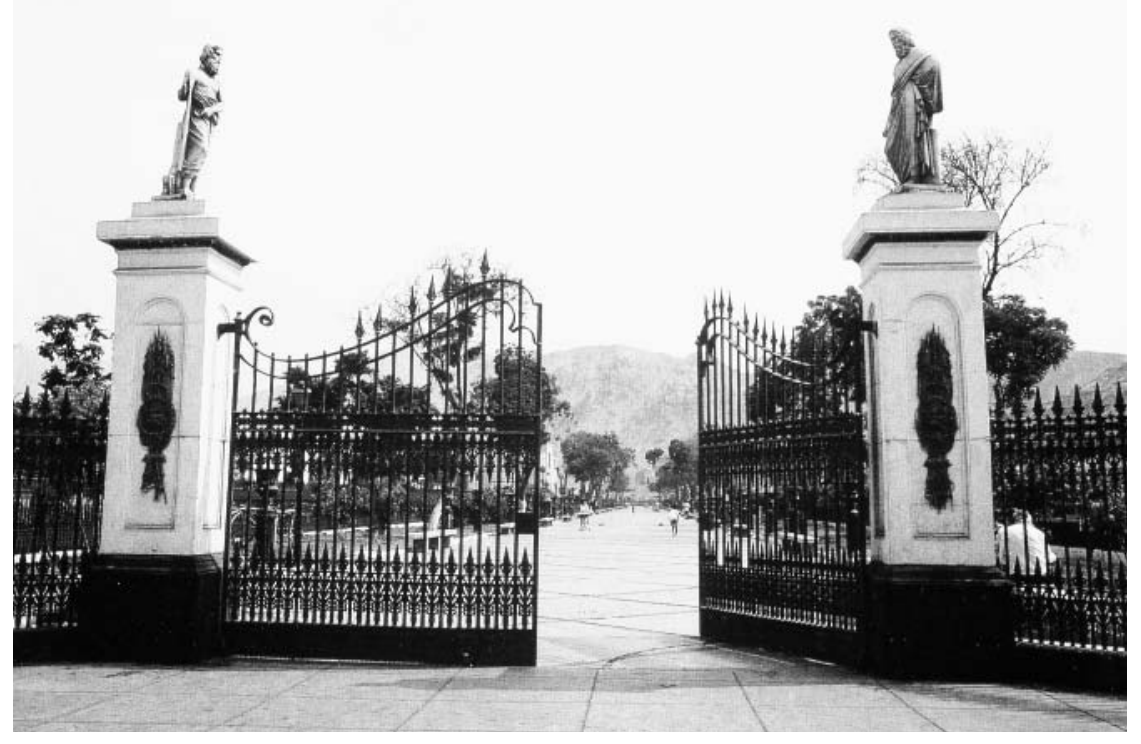

Figura 23. El Rimac, Lima, Vista hacia el norte de la Alameda de los D escalzos.

obras públicas que mandó construir el virrey Amat. Terminado de disfrutar el ritual de la corrida de toros, el séquito virreinal hubiera entonces podido completar el circuito del paseo a través de la Alameda N ueva (figura 29), que bordeando la ribera del río Rimac daba nuevamente acceso al Puente de Piedra, para retornar otra vez a la Plaza M ayor (figura ig).

Resulta difícil recordar hoy todo el esplendor y colorido que debió caracterizar ese recorrido, pero los dibujos de Leonce Angrand (I808-1885) y las pinturas de Juan M auricio Rugendas (1802-1858) del siglo pasado son muy elocuentes (figura 30). Los edificios que se han perdido han irreversiblemente erosionado las calles y los espacios abiertos que en una oportunidad se sumaron para crear un todo armonioso. Angrand pudo todavía captar algo del espíritu del lugar al referirse a los bellos paseos de Lima en i866:

Las soledades de la Alameda de los D escalzos son turbadas una vez más en otra circunstancia, en la época del despertar de la naturaleza, cuando la vegetación, adormecida durante las sequías del verano, renace bajo la influencia de los primeros rocíos de otoño. Se ve entonces las cimas de los cerros que bordean el pie de la cordillera, áridos y desolados durante la estación seca, cubrirse repenti- 
DOI: http://dx.doi.org/10.22201/iie.18703062e.1999.74-75.1874

172 HUMBERTO RODRÍGUEZ CAMILLONI

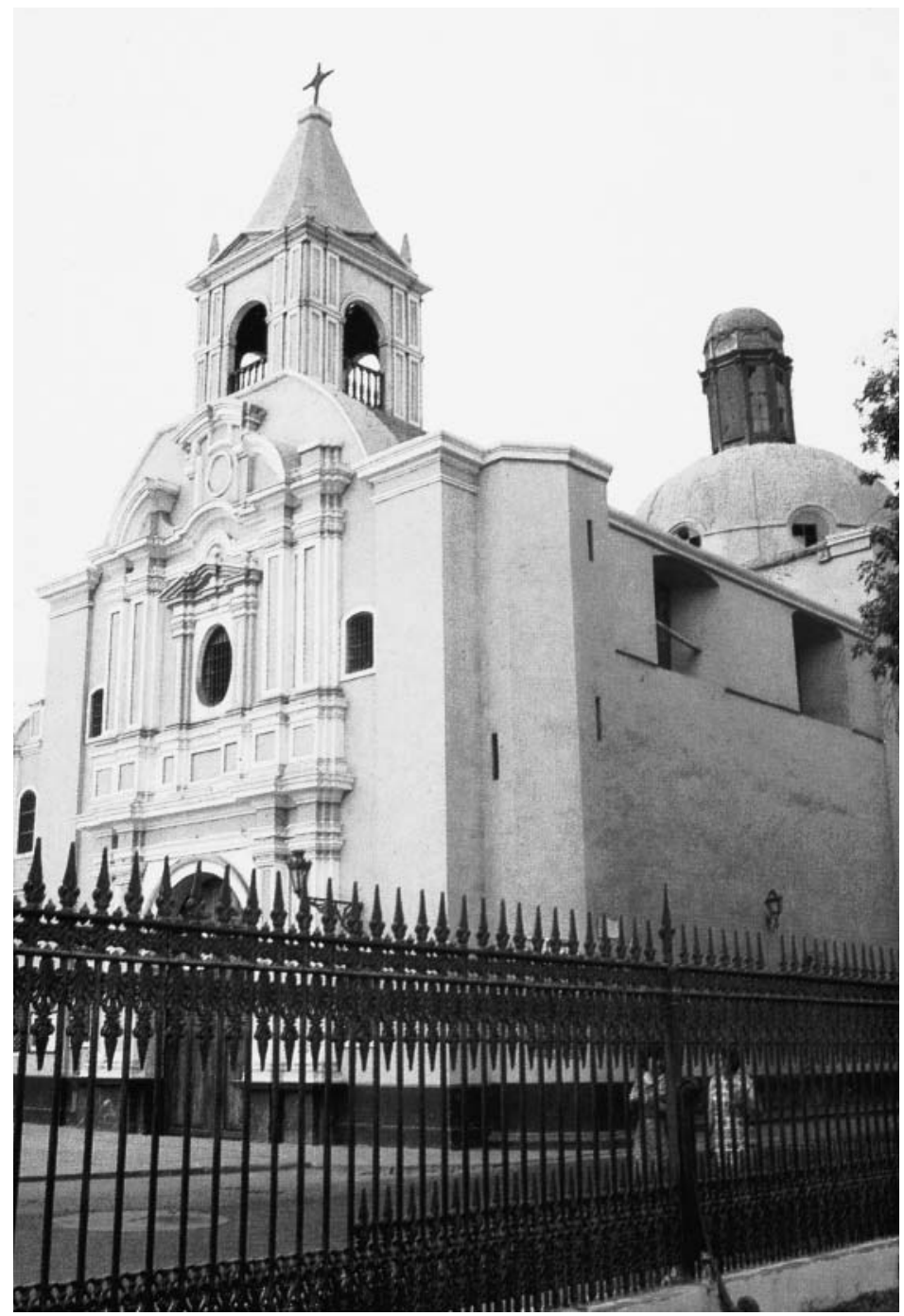

Figura 24. El Rimac, Lima, I glesia de Santa Liberata. 
DOI: http://dx.doi.org/10.22201/iie.18703062e.1999.74-75.1874

MANUEL DE AMAT Y JUNYENT Y LA NAVONA DE LIMA

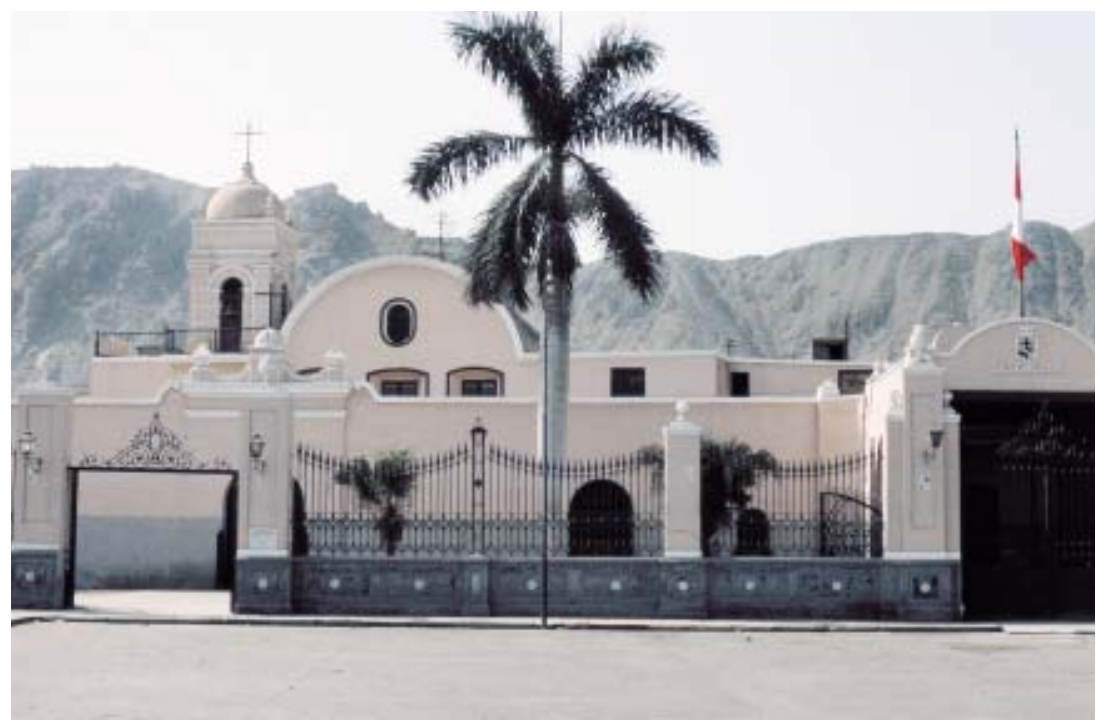

Figura 25. El Rimac, Lima, Iglesia y monasterio de los D escalzos.

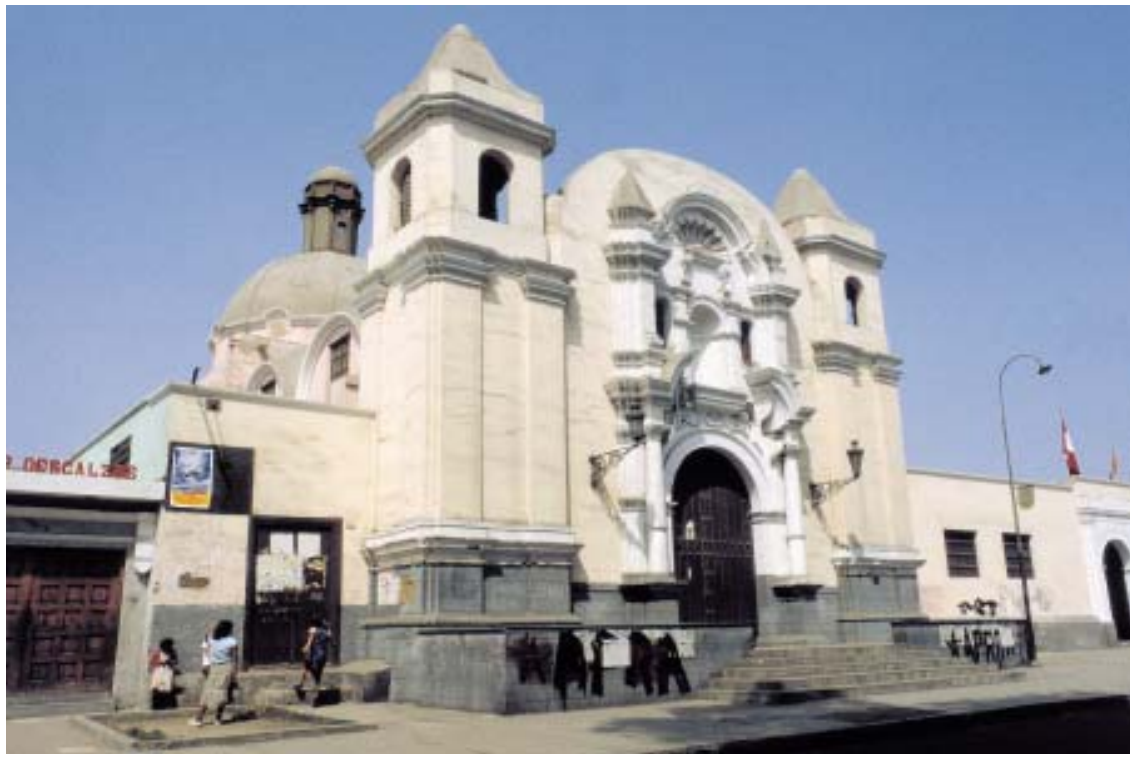

Figura 26. El Rimac, Lima, I glesia de N uestra Señora del Patrocinio. 


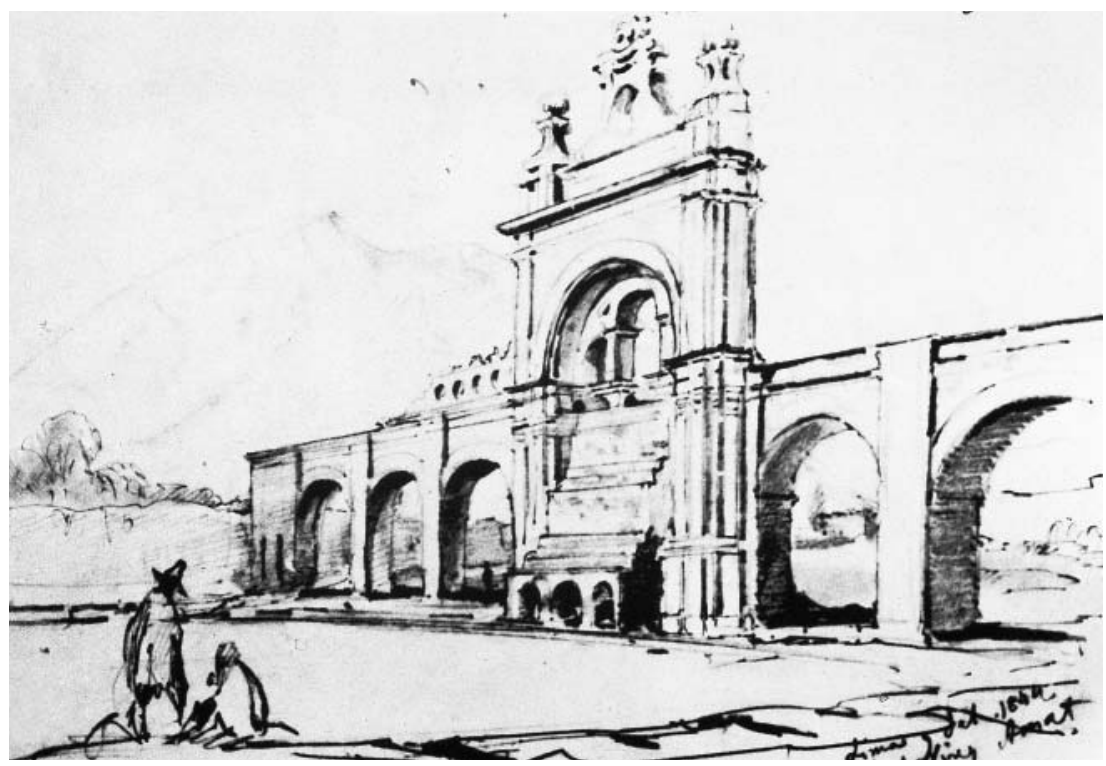

Figura 27. Juan M auricio Rugendas, El Paseo de Aguas, dibujo al lápiz de i844.

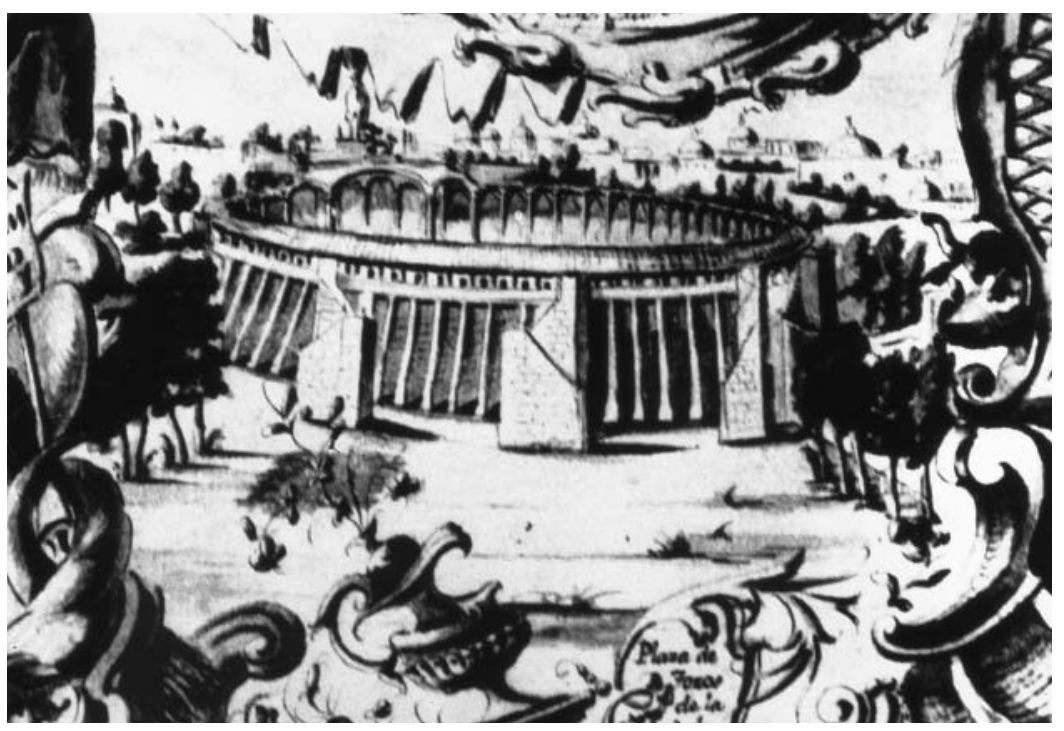

Figura 28. El Rimac, Lima, Plaza detorosdeAcho. M s. 400 de la Biblioteca Central de C ataluña. 
Figura 29. El Rimac, Lima, La Alameda de Acho, según una litografía de C harles Rivière de 1867.

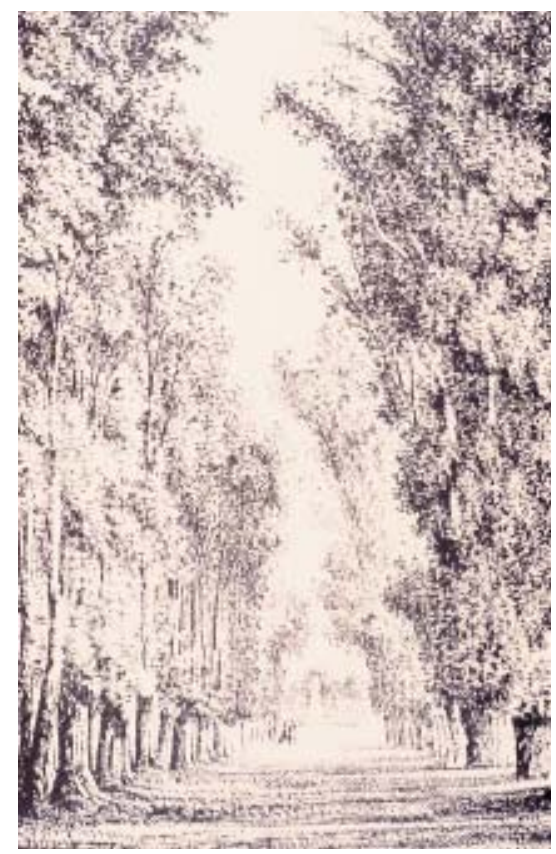

namente con un rico tapiz de flores y de verdor, a los que la humedad de las neblinas concede una efímera existencia; pronto estas improvisadas praderas extienden sus mantos matizados de un amarillo deslumbrante hasta el fondo de los vallecillos más cercanos a la ciudad. El aire aromado de la montaña, traído por la brisa deletérea, llega al anochecer hasta los muros de la ciudad y hace vibrar todos los corazones a la espera del día. Al fin se eleva el alba del día de San Juan, saludado por el repique jubiloso de las campanas innumerables de la ciudad; en seguida la alegría se extiende a todas las clases y se apodera de esas imaginaciones a las que la emoción invade cada vez que la naturaleza viene a despertar los sentidos con al gún nuevo encantamiento. ${ }^{30}$

En 1938 se demolió la casa de la Perricholi (figura ${ }_{17}$ ) para dar paso a las instalaciones de una fábrica de cerveza. Pocas en realidad son las estructuras

30. Leonce Angrand, "C arta sobre los jardines de Lima”, i866, en I magen del Perú en el siglo xıx, Lima, I972, p. I67. 


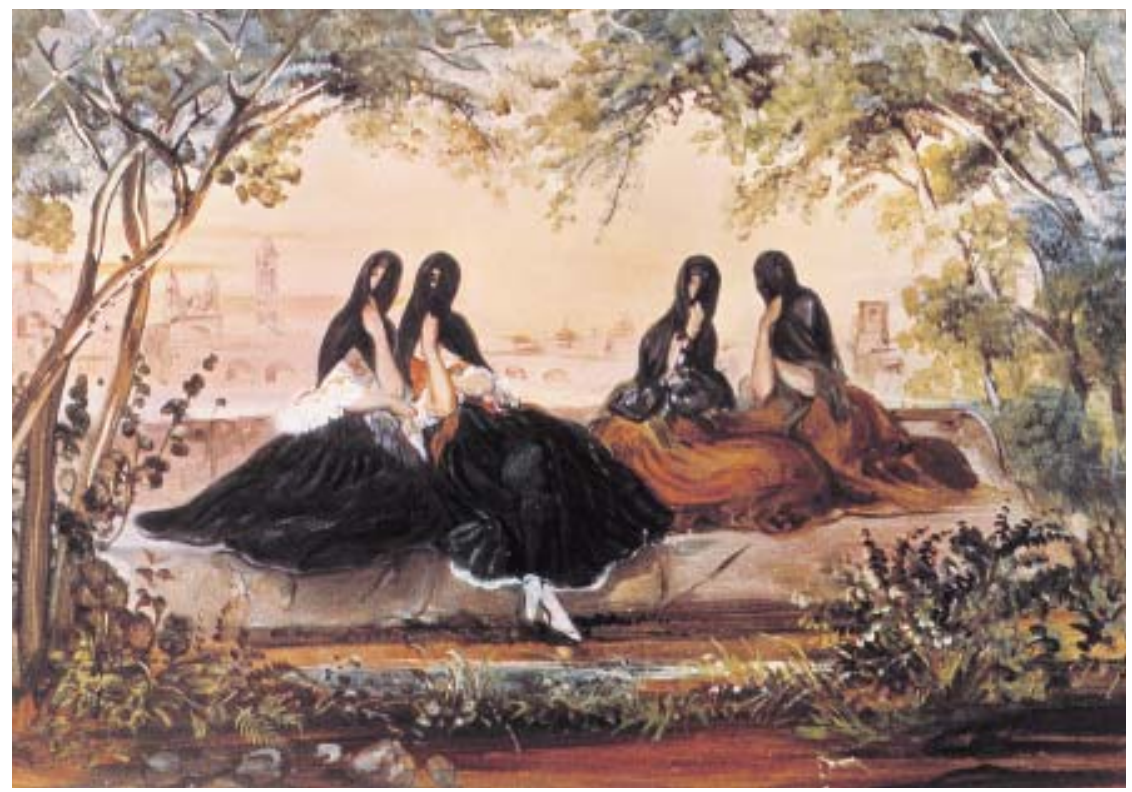

Figura 3o. Juan M auricio Rugendas, T apadas en la Alameda, óleo sobre papel, C. I843.

que han perdurado hasta la fecha, de lo que fue en su época La N avona del virrey Amat. Irónicamente, con el paso del tiempo y con mucho menos agua de la que imaginó su creador, hasta su nombre original fue cambiado por el de Paseo de Aguas, que es el que se usa comúnmente hoy en día. Sólo ha quedado como testimonio de la gran visión del virrey arquitecto la fuente escenográfica (figura 2), parcialmente restaurada en 1982. El impulso creativo de Amat lo llevó a introducir una nueva concepción arquitectónica y urbanística de marcado dinamismo espacial con la cual se cerraría otro gran ciclo de la historia de la arquitectura virreinal limeña. Pensando en grande, Amat quiso que la Ciudad de los Reyes aspirara a ser también una ciudad eterna, pero el destino no lo permitió. Una vez más, la vida nos recuerda que, al igual que el reflejo en el espejo de agua de una fuente, la realidad es sólo una ilusión. s 